\title{
Digital subtraction of temporally sequential mammograms for improved detection and classification of microcalcifications
}

\author{
Kosmia Loizidou $^{1 *}$ D, Galateia Skouroumouni ${ }^{2}, \operatorname{Costas}$ Pitris $^{1}$ and Christos Nikolaou ${ }^{3}$
}

\begin{abstract}
Background: Our aim was to demonstrate that automated detection and classification of breast microcalcifications, according to Breast Imaging Reporting and Data System (BI-RADS) categorisation, can be improved with the subtraction of sequential mammograms as opposed to using the most recent image only.

Methods: One hundred pairs of mammograms were retrospectively collected from two temporally sequential rounds. Fifty percent of the images included no (BI-RADS 1) or benign (BI-RADS 2) microcalcifications. The remaining exhibited suspicious findings (BI-RADS 4-5) in the recent image. Mammograms cannot be directly subtracted, due to tissue changes over time and breast deformation during mammography. To overcome this challenge, optimised preprocessing, image registration, and postprocessing procedures were developed. Machine learning techniques were employed to eliminate false positives (normal tissue misclassified as microcalcifications) and to classify the true microcalcifications as BI-RADS benign or suspicious. Ninety-six features were extracted and nine classifiers were evaluated with and without temporal subtraction. The performance was assessed by measuring sensitivity, specificity, accuracy, and area under the curve (AUC) at receiver operator characteristics analysis.
\end{abstract}

Results: Using temporal subtraction, the contrast ratio improved $\sim 57$ times compared to the most recent mammograms, enhancing the detection of the radiologic changes. Classifying as BI-RADS benign versus suspicious microcalcifications, resulted in $90.3 \%$ accuracy and 0.87 AUC, compared to $82.7 \%$ and 0.81 using just the most recent mammogram $(p=0.003)$.

Conclusion: Compared to using the most recent mammogram alone, temporal subtraction is more effective in the microcalcifications detection and classification and may play a role in automated diagnosis systems.

Keywords: Breast cancer, Mammography, Radiographic image interpretation (computer-assisted), Retrospective studies, Machine learning

\footnotetext{
* Correspondence: cloizi01@ucy.ac.cy

${ }^{1}$ KIOS Research and Innovation Center of Excellence, Department of Electrical and Computer Engineering, University of Cyprus, 1 Panepistimiou Avenue,

Aglantzia, 2109 Nicosia, Cyprus

Full list of author information is available at the end of the article
}

\section{Springer Open}

(c) The Author(s). 2021 Open Access This article is licensed under a Creative Commons Attribution 4.0 International License, which permits use, sharing, adaptation, distribution and reproduction in any medium or format, as long as you give appropriate credit to the original author(s) and the source, provide a link to the Creative Commons licence, and indicate if changes were made. The images or other third party material in this article are included in the article's Creative Commons licence, unless indicated otherwise in a credit line to the material. If material is not included in the article's Creative Commons licence and your intended use is not permitted by statutory regulation or exceeds the permitted use, you will need to obtain permission directly from the copyright holder. To view a copy of this licence, visit http://creativecommons.org/licenses/by/4.0/. 


\section{Key points}

- The contrast ratio of the subtracted images was improved $~ 57$ times, compared to that of the recent images without preprocessing.

- Eighteen per cent of pre-existing Breast Imaging Reporting and Data System (BI-RADS) category 2 findings were effectively removed and the remaining were detected with an accuracy of $94.1 \%$.

- Accuracy and area under the curve of the classification of microcalcifications as BI-RADS 2 versus BI-RADS 4 or 5 were significantly higher with the use of temporal subtraction, compared to using only the most recent mammogram $(p=0.003)$.

\section{Background}

Breast cancer screening with mammography is an effective approach to reduce breast cancer mortality. However, the large population involved and the use of double reading increases the workload and can limit the efficiency of the screening process [1]. To further exacerbate the challenge, various types of abnormalities are associated with breast cancer, including microcalcifications [2]. They can be benign or form microcalcification clusters possibly suspicious, to be managed appropriately. For the BI-RADS classification of microcalcifications as benign or suspicious, morphology, distribution, and change over time are key parameters [3]. Computeraided diagnosis (CAD) systems are being explored as a means to improve the specificity of the classification of mammographic anomalies without compromising the sensitivity [4]. Several groups [5-7] have assessed the use of CAD systems for the detection of microcalcifications present in the most recent mammographic views, with sensitivity and specificity in the range of $82-89 \%$ and $87-88 \%$, respectively, when discriminating between benign and suspicious microcalcifications. The main drawback of those systems is the considerable number of false positives (FPs) per image, that can range up to $1-3$, which reduces their clinical applicability [8]. In addition, they provide no information regarding the presence of those abnormalities in previous mammographic sessions.

In temporal analysis, mammograms from multiple prior examinations are utilised. When prior information is available for direct comparison, abnormalities can be detected at an earlier stage and the radiologists feel more confident of their assessment [9]. Some studies have attempted to combine information from prior and recent mammographic views to reduce the FP and recall rates [9-14]. Prior and recent images were coarsely registered based on anatomical features (e.g., nipple, skin, centre of mass which is the mean value across each dimension), and the locations of recently identified microcalcifications in the prior image were identified by regional registration, i.e., searching around the location of the recent finding. Combining the features from both images resulted in an improved specificity, specificity, and reduced FPs rates. However, temporal analysis offers no benefit, over using just the recent mammographic view, when the findings are new with no traces of abnormality in the prior screening [11].

Going a step further, temporal subtraction begins with using both global and local features to register the entire breast areas of the recent and prior mammographic views. This allows direct subtraction of the images, digitally removing unchanged regions from the recent mammographic view, further delineating subtle recent changes, including microcalcifications $[15,16]$. The objective of this study was to evaluate the effect of the subtraction of temporally sequential mammograms to eliminate unchanged features and improve the detection and classification of microcalcifications into benign and suspicious, based on their BI-RADS category. For comparison, the detection and classification methodologies were also applied to the most recent images without temporal subtraction.

\section{Methods \\ Study population}

The current study expands on prior published work [16]. From the 100 participants that were eventually included, 80 were previously used for the purposes of describing the technical details of the algorithms employed. For this retrospective study, 100 pairs of fullfield digital mammograms were collected, between 2012 and 2020, from various local hospitals (Nicosia General Hospital, Limassol General Hospital, Cyprus population screening program Aglantzia and Linopetra), performed by women ( 38 to 83 years of age, $60.07 \pm 7.09$, mean \pm standard deviation) with either no microcalcifications or BI-RADS benign (normal population) or BI-RADS suspicious microcalcifications (suspicious population) in their current mammograms. A BI-RADS normal or benign prior mammogram (average interval of 2.2 years) was required for inclusion in the study (Fig. 1). The normal population was selected to form an age-matched group compared to the patients with BI-RADS suspicious microcalcifications. The study was approved by the appropriate Institutional Review Board (Cyprus National Bioethics Committee \#ЕЕВK ЕП 2020.01.144) and informed consent was retrospectively collected.

For every participant, two mammographic views (cranio-caudal and medio-lateral oblique) of the breast showing the presence of micorcalcifications, from two sequential screening rounds, were included for a total of 400 images. A radiologist (C.N. with 10 years of experience) identified the patients to be included, according to 


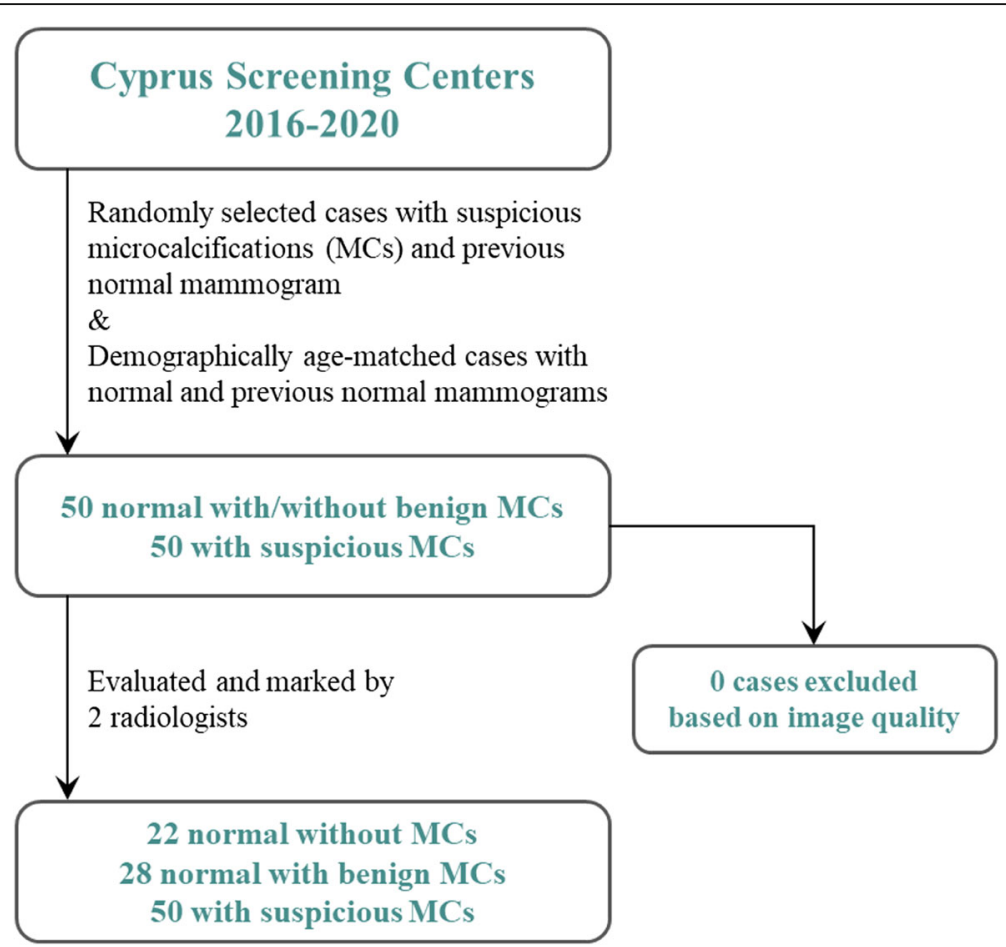

Fig. 1 Flowchart of study population selection. MCs Microcalcifications

Table 1 Characteristics of the population and digital mammography examinations selected for the study

\begin{tabular}{|c|c|c|c|}
\hline \multirow[t]{2}{*}{ Variable } & \multicolumn{3}{|l|}{ Population } \\
\hline & $\begin{array}{l}\text { BI-RADS normal } \\
(n=50)\end{array}$ & $\begin{array}{l}\text { BI-RADS suspicious } \\
(n=50)\end{array}$ & $\begin{array}{l}\text { Total } \\
(n=100)\end{array}$ \\
\hline \multicolumn{4}{|l|}{ Patient age } \\
\hline Mean \pm standard deviation & $59.42 \pm 5.97$ & $60.72 \pm 8.00$ & $60.07 \pm 7.09$ \\
\hline Median & 59 & 61.5 & 59.5 \\
\hline Range & $47-75$ & $38-83$ & $38-83$ \\
\hline Interquartile range & $55-64$ & $55.75-66.25$ & $55-65$ \\
\hline \multicolumn{4}{|l|}{ BI-RADS breast density } \\
\hline$a$ & 5 & 5 & 10 \\
\hline$b$ & 33 & 24 & 57 \\
\hline c & 10 & 18 & 28 \\
\hline$d$ & 2 & 3 & 5 \\
\hline \multicolumn{4}{|l|}{ BI-RADS classification } \\
\hline 1 & 22 & 0 & 22 \\
\hline 2 & 28 & 0 & 28 \\
\hline 3 & 0 & 0 & 0 \\
\hline $4 a$ & 0 & 27 & 27 \\
\hline $4 b$ & 0 & 15 & 15 \\
\hline $4 c$ & 0 & 6 & 6 \\
\hline 5 & 0 & 2 & 2 \\
\hline
\end{tabular}


the criteria specified above, and along with a second radiologist (G.S. with 2 years of experience), assessed the mammograms for assigning the BI-RADS category and marked the location of the microcalcifications. Interobserver agreement, i.e., microcalcifications marked by both observers, was estimated at $97.1 \%$ for benign (BIRADS 2) and $98.2 \%$ for suspicious (BI-RADS 4-5) microcalcifications; differences were resolved by consensus. A summary of the study population is shown in Table 1 . Fifty percent of the mammograms came from healthy participants (28 with only BI-RADS benign microcalcifications in the prior and recent mammographic views and 22 with no visible microcalcifications). In the remaining $50 \%$, at least one new BI-RADS suspicious microcalcification was present in the most recent mammographic view. The ground truth was based on the BIRADS category, as evaluated by the radiologists, without any confirmation by follow-up (for "benign" lesions), or biopsy (for "suspicious" lesions). This data set not only included temporally sequential mammograms, but also precise annotation of each individual microcalcification to be used as a reference (Fig. 2). The data set included a total of 629 microcalcifications, 515 BI-RADS 2 and
114 BI-RADS 4 or 5 . The size of the mammographic views was $4096 \times 3328$ pixels, in an 8-bit DICOM format. This data is publicly available (https://doi.org/10. 5281/zenodo.5036062).

\section{Image registration, subtraction, and segmentation}

Supplemental Fig. S1 shows the diagram of the proposed methodology for detection and BI-RADS classification of microcalcifications. The procedure began with image preprocessing for normalisation, border removal [17], and gamma correction [18]. Next, each prior mammographic view was co-registered to the most recent one. Image registration is a critical step in temporal subtraction, since it corrects for the changes that occur in the breast over time and due to deformation between mammograms. Demons registration [19], a non-rigid method based on local flows, was employed due to superior performance compared to other common approaches [20]. The prior registered mammographic view was subsequently subtracted from the recent, effectively removing the regions that have remained unchanged since the previous exam. The contrast ratio of the subtracted image, i.e., the ratio of the maximum divided by the average

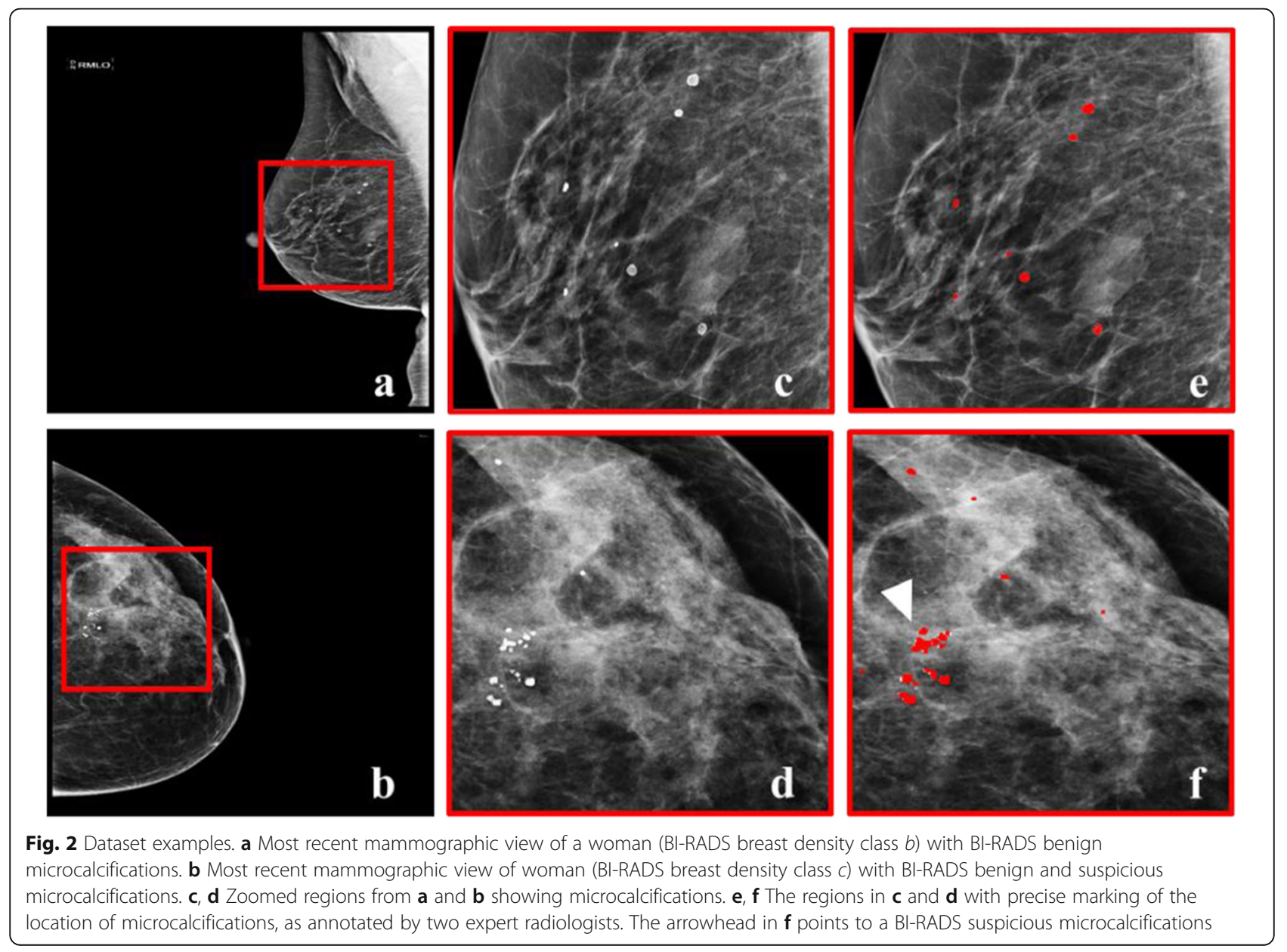


intensity, was compared to that of the recent mammographic view to evaluate the effectiveness of the removal of the background. Furthermore, the capability of the subtraction to remove unchanged microcalcifications, thus reducing the FP rate, was also assessed. After range filtering [21], the intensity values of each image were converted to binary, i.e., 0 or 1 , using an intensity threshold, obtained by optimising the global BI-RADS classification rate. The binary image was further processed morphologically. The operations of closing (removing small unconnected regions) and opening (filling small gaps) were applied and the remaining regions were considered as possible microcalcifications.

\section{Feature extraction and selection for classification}

To differentiate the true microcalcifications from other tissue and, subsequently, the BI-RADS benign from the BI-RADS suspicious microcalcifications, using machine learning algorithms, several features were estimated from every possible region containing microcalcifications. Ninety-six, shape, intensity first order statistic, and grey-level co-occurrence matrix (GLCM) features were extracted [22-24]. The GLCM was calculated at $0^{\circ}, 45^{\circ}$, $90^{\circ}$, and $135^{\circ}$ and 5-, 15-, and 25-pixel offset. The mean and standard deviation of each GLCM texture property were obtained, resulting in 72 features. Hypothesis test $(t$-test) [25] and feature importance [26] were employed to identify the most significant features and further evaluate their contribution to the classification.

\section{Training and comparison of classifier designs}

For the BI-RADS classification, 9 classifiers were evaluated: 9-nearest neighbors [1], decision trees [27], random forest [27], multi-layer perceptron [28], adaptive boosting [29], bagging [30], gradient boosting [31], and ensemble voting [32]. In addition, different neural network configurations were evaluated using Python (Python Software Foundation, Wilmington, USA, v. 3.7.7) and Keras (Keras Special Interest Group, François Chollet, Mountain View, USA, v. 2.3.1) [33]. The resulting, most suitable, network consisted of 7 fully connected layers, with 986,738 trainable parameters. Rectified linear unit was used as an activation function and adaptive dropout regularisation was included every two hidden layers. Gaussian noise was added after dropout, as a regularisation term, in order to increase the robustness of the network. Batch size was set to 128 and the network was trained for 100 epochs. Traditional classifiers were selected based on their prior application to mammography.

The complete dataset was used during the training stage with leave-one-patient-out (LOPO) crossvalidation. This cross-validation approach was critical in order to avoid bias from including images of the same patient in both test and training sets. K-fold crossvalidation was also considered, again by dividing the patients into folds. Initially, the possible microcalcifications were classified as normal tissue or true microcalcifications and, subsequently, the true microcalcifications were classified as BI-RADS benign or suspicious.

\section{Detection and classification using the most recent mammogram alone}

For comparison purposes, the same classification approach was optimised and applied to the most recent mammograms, without temporal subtraction, to verify the benefit of temporal subtraction.

\section{Statistical analysis}

The classification performance was evaluated by computing the sensitivity, specificity, accuracy, and the area under the curve (AUC) at receiver operator characteristics analysis. The cut-off values for calculating sensitivity and specificity were selected optimally so that BI-RADS false positive and false negative numbers are minimised, i.e., the cross point of the positive and negative distributions. In the comparison of the results from using just the most recent mammogram, the Fisher test was used with a level of statistical significance set to $p=0.05$.

\section{Results}

\section{Image registration, subtraction, and segmentation}

Image registration and subtraction yielded an average $72 \%$ reduction of image intensity, a result of removing structures that have remained unchanged between screenings. The average contrast ratio of the subtracted images was $\sim 57$ times higher compared to the recent mammographic view (Fig. 3). Eighteen percent of old BIRADS benign microcalcifications were effectively removed (Table 2). It is also important to note that none of the BI-RADS suspicious microcalcifications were removed by this process (Fig. 4). The processing time for these operations was an average of $\sim 15 \mathrm{~min}$ per image pair (Intel $^{\bullet}$ Core $^{\mathrm{Tx}}$ i7 $2 \mathrm{GHz}$; Intel Corp., Santa Clara, CA, USA).

\section{Feature extraction and selection for classification}

Features of microcalcifications were extracted from the images as described in the previous section. Based on the results of $t$-test and feature importance, the features with the most significant contribution to classification were identified for each classification round. The details of the features that have been selected in each case can be found in Supplemental Table S1.

\section{Detection and classification using temporal subtraction}

The results of the detection of the microcalcifications are summarised in Table 3. The sensitivity, specificity, accuracy, and AUC of the different methods were in the range of $72.8-82.3 \%, 83.7-97 \%, 83.5-95 \%$, and 0.82 


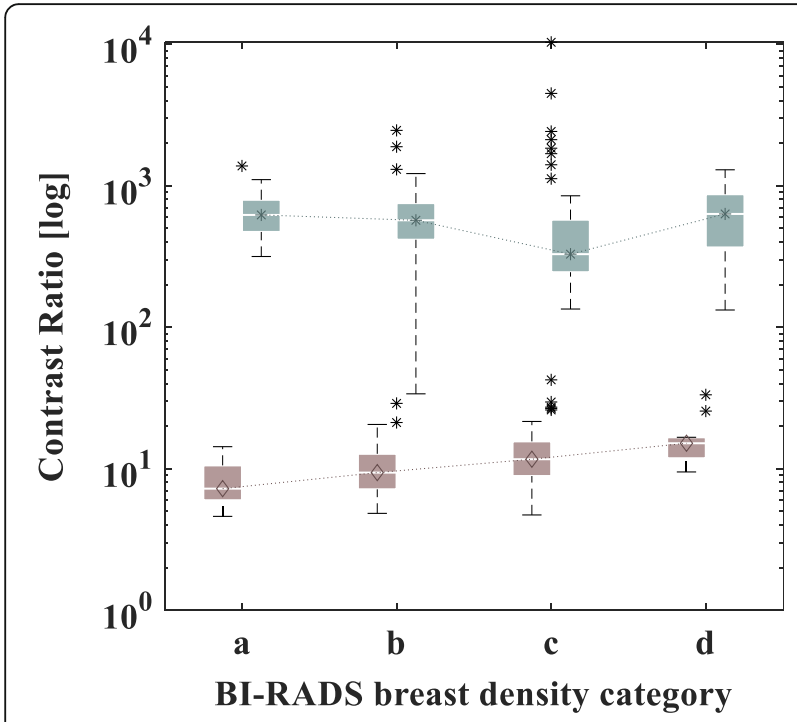

Fig. 3 Plot comparing the contrast ratio, in logarithmic scale, of the unprocessed recent image and the image created by temporal subtraction, for the four categories of BI-RADS breast density. The contrast ratio increased indicating that temporal subtraction is successful for all breast densities

$-0.88 \%$, respectively. Based on the AUC, the most successful classification scheme was the ensemble voting with $81.4 \%$ sensitivity, $95.5 \%$ specificity, $94.1 \%$ accuracy, and 0.88 AUC. The application of k-fold cross-validation (Fig. 5a), using $k=4,5$, and 10, verified that the performance remained approximately at the same level.

The optimisation of the various classifiers for the classification of microcalcifications as benign or suspicious according to their BI-RADS category, using LOPO cross-validation, resulted in the outcomes summarised in Table 4. The sensitivity, specificity, accuracy and AUC were in the range of $57.9-84.2 \%, 77.8-92.2 \%, 79.0$ $-90.3 \%$ and, $0.70-0.87 \%$, respectively. Based on the AUC, the most successful classification scheme was again ensemble voting with $81.6 \%$ sensitivity, $92.2 \%$ specificity, 90.3\% accuracy, and 0.87 AUC. For this classification round, only 13-fold cross-validation was applied (Fig. 6a) due to the smaller number of patients with microcalcifications (i.e., 78 patients with true microcalcifications, 50 BI-RADS suspicious, and 28 BIRADS normal with benign microcalcifications). Example images visually demonstrating the classification outcome, using temporal subtraction, where BI-RADS benign and suspicious microcalcifications were correctly identified, are shown in Supplemental Fig. S2.

\section{Detection and classification using the most recent mammogram alone}

Table 3 shows the classification results for the identification of true microcalcifications using features selected only from the most recent mammographic view (Supplemental Table S1) and the same classifiers as before optimised for these features. The best classification performance was achieved using ensemble voting with $72.7 \%$ sensitivity, $96.5 \%$ specificity, $94.1 \%$ accuracy, and 0.83 AUC. Subsequently, the true microcalcifications were classified as BI-RADS benign or suspicious and the results are presented in Table 4. Again, the ensemble voting was the most successful method, providing $78.9 \%$ sensitivity, $83.5 \%$ specificity, $82.7 \%$ accuracy, and 0.81 AUC. As before, k-fold cross-validation was also performed, using the same values of $k$ (Figs. $5 \mathrm{~b}$ and $6 \mathrm{~b}$ ) showing that the algorithm was also stable and robust.

\section{Discussion}

A method for the detection and classification of microcalcifications, according to their BI-RADS category, from the subtraction of temporally sequential mammographic views was developed. The aim of this work was to combine temporal subtraction with machine learning in order to enhance the contrast ratio, eliminate the radiologically unchanged microcalcifications and, most importantly, improve the classification accuracy of microcalcifications as benign or suspicious, based on their BI-RADS categories. For effective and efficient subtraction of the prior from the most recent mammographic view, preprocessing, registration, and postprocessing procedures were applied. Machine learning techniques were then used to eliminate the FPs, i.e., normal tissue misclassified as microcalcifications, and, furthermore, to classify the true microcalcifications as BI-

Table 2 Elimination of old microcalcifications that appear in both screening rounds, in BI-RADS normal and suspicious mammograms

\begin{tabular}{|c|c|c|c|c|c|c|c|}
\hline Mammograms & $\begin{array}{l}\text { New } \\
\text { microcalcifications }\end{array}$ & $\begin{array}{l}\text { Old } \\
\text { microcalcifications }\end{array}$ & $\begin{array}{l}\text { Overlapping } \\
\text { microcalcifications }\end{array}$ & $\begin{array}{l}\text { Overlap } \\
\text { (\%) }\end{array}$ & & $\begin{array}{l}\text { Reduction } \\
\text { (\%) }\end{array}$ & \\
\hline $\begin{array}{l}\text { BI-RADS normal } \\
(n=200)\end{array}$ & 248 & 224 & 54 & $54 / 224$ & (24.1) & $54 / 248$ & $(21.8)$ \\
\hline $\begin{array}{l}\text { BI-RADS suspicious } \\
(n=200)\end{array}$ & 398 & 319 & 64 & $64 / 319$ & (20.1) & $64 / 398$ & $(16.1)$ \\
\hline $\begin{array}{l}\text { Total } \\
(n=400)\end{array}$ & 646 & 543 & 118 & $118 / 543$ & $(21.7)$ & $118 / 646$ & $(18.3)$ \\
\hline
\end{tabular}



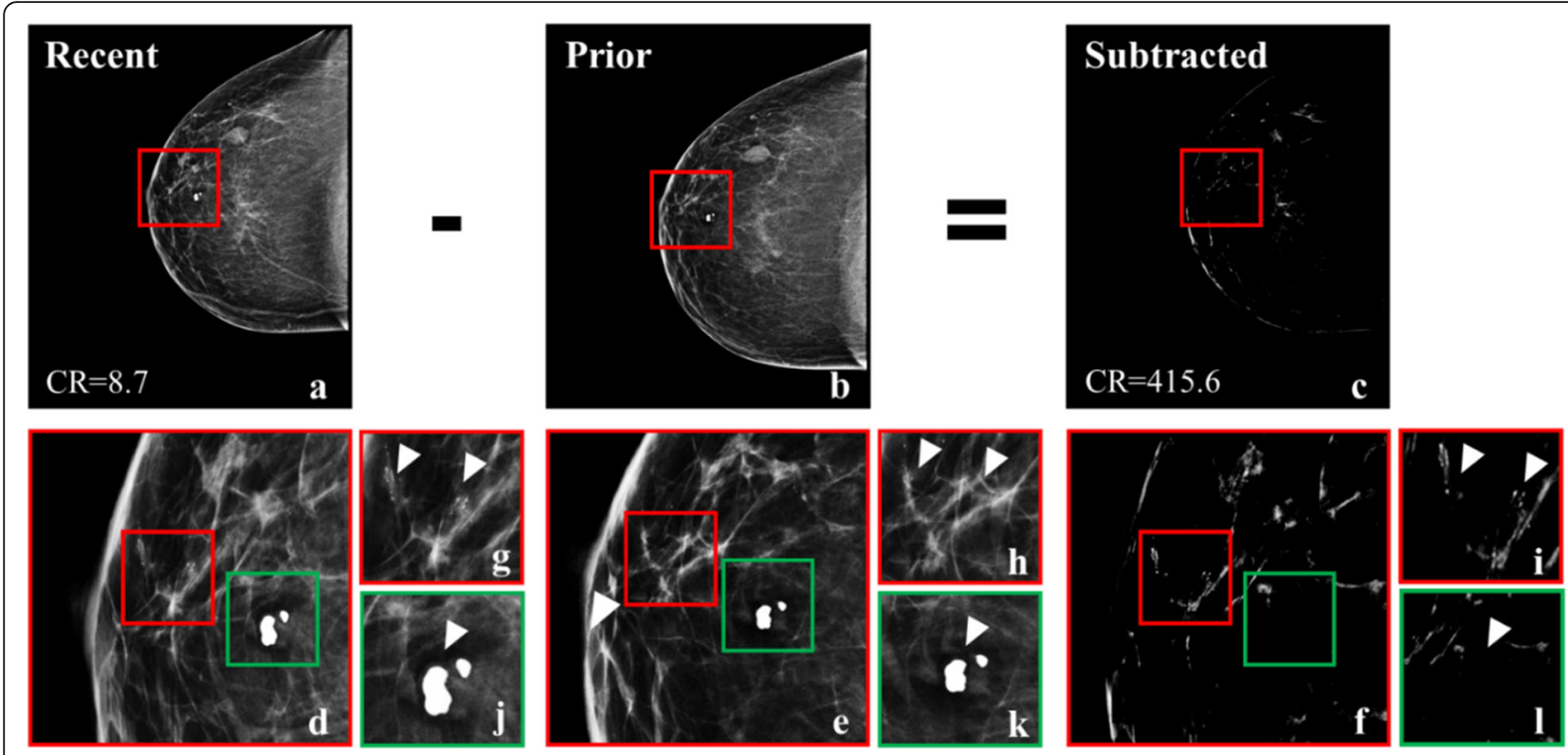

Fig. 4 Example of temporal subtraction in a woman (BI-RADS breast density class $b$ ) with BI-RADS benign and suspicious microcalcifications. a Most recent mammographic view. $\mathbf{b}$ Prior mammographic view. $\mathbf{c}$ The result of subtracting the registered version of $\mathbf{b}$ from $\mathbf{a}$, where the contrast ratio has increased 92 times after subtraction. $\mathbf{d}-\mathbf{f}$ Zoomed regions marked by the red squares in $\mathbf{a}-\mathbf{c}$. $\mathbf{g}$-i Zoomed regions marked by the red squares in $\mathbf{d}-\mathbf{f}$ where the arrowheads point to new BI-RADS suspicious microcalcifications, which were not subtracted. (j-I) Zoomed regions marked by the green squares in $\mathbf{d}-\mathbf{f}$ where the arrow points to pre-existing BI-RADS benign microcalcifications, which were completely subtracted. CR Contrast ratio

Table 3 Comparison of the classification results of the possible microcalcifications as normal tissue or radiologically true microcalcifications with temporal subtraction (TS) of mammograms or using only the most recent mammograms (RM), in a leaveone-patient-out cross-validation scheme

\begin{tabular}{|c|c|c|c|c|c|c|c|c|c|c|c|}
\hline \multirow{2}{*}{$\begin{array}{l}\text { Classifier } \\
\text { 9-Nearest } \\
\text { neighbors }\end{array}$} & \multicolumn{3}{|c|}{$\begin{array}{l}\text { Sensitivity } \\
\text { (\%) }\end{array}$} & \multicolumn{3}{|c|}{$\begin{array}{l}\text { Specificity } \\
(\%)\end{array}$} & \multicolumn{2}{|c|}{$\begin{array}{l}\text { Accuracy } \\
\text { (\%) }\end{array}$} & \multicolumn{3}{|c|}{ AUC } \\
\hline & $\begin{array}{l}\text { TS } \\
\text { RM }\end{array}$ & $\begin{array}{l}501 / 629 \\
469 / 629\end{array}$ & $\begin{array}{l}(79.7) \\
(74.6)\end{array}$ & $\begin{array}{l}\text { TS } \\
\text { RM }\end{array}$ & $\begin{array}{l}4928 / 5739 \\
4593 / 5739\end{array}$ & $\begin{array}{l}(85.9) \\
(80.0)\end{array}$ & $\begin{array}{l}\text { TS } \\
\text { RM }\end{array}$ & $\begin{array}{l}5429 / 6368 \\
5062 / 6368\end{array}$ & $\begin{array}{l}(85.3) \\
(79.5)\end{array}$ & $\begin{array}{l}\text { TS } \\
\text { RM }\end{array}$ & $\begin{array}{l}0.83 \\
0.76\end{array}$ \\
\hline $\begin{array}{l}\text { Decision } \\
\text { trees }\end{array}$ & $\begin{array}{l}\text { TS } \\
\text { RM }\end{array}$ & $\begin{array}{l}458 / 629 \\
392 / 629\end{array}$ & $\begin{array}{l}(72.8) \\
(62.3)\end{array}$ & $\begin{array}{l}\text { TS } \\
\text { RM }\end{array}$ & $\begin{array}{l}5311 / 5739 \\
5234 / 5739\end{array}$ & $\begin{array}{l}(92.5) \\
(91.2)\end{array}$ & $\begin{array}{l}\text { TS } \\
\text { RM }\end{array}$ & $\begin{array}{l}5769 / 6368 \\
5626 / 6368\end{array}$ & $\begin{array}{l}(90.6) \\
(88.4)\end{array}$ & $\begin{array}{l}\text { TS } \\
\text { RM }\end{array}$ & $\begin{array}{l}0.83 \\
0.78\end{array}$ \\
\hline $\begin{array}{l}\text { Random } \\
\text { forest }\end{array}$ & $\begin{array}{l}\text { TS } \\
\text { RM }\end{array}$ & $\begin{array}{l}484 / 629 \\
421 / 629\end{array}$ & $\begin{array}{l}(77.0) \\
(66.9)\end{array}$ & $\begin{array}{l}\text { TS } \\
\text { RM }\end{array}$ & $\begin{array}{l}5565 / 5739 \\
5591 / 5739\end{array}$ & $\begin{array}{l}(97.0) \\
(97.4)\end{array}$ & $\begin{array}{l}\text { TS } \\
\text { RM }\end{array}$ & $\begin{array}{l}6049 / 6368 \\
6012 / 6368\end{array}$ & $\begin{array}{l}(95.0) \\
(94.4)\end{array}$ & $\begin{array}{l}\text { TS } \\
\text { RM }\end{array}$ & $\begin{array}{l}0.87 \\
0.82\end{array}$ \\
\hline $\begin{array}{l}\text { Multilayer } \\
\text { perceptron }\end{array}$ & $\begin{array}{l}\text { TS } \\
\text { RM }\end{array}$ & $\begin{array}{l}510 / 629 \\
470 / 629\end{array}$ & $\begin{array}{l}(81.1) \\
(74.7)\end{array}$ & $\begin{array}{l}\text { TS } \\
\text { RM }\end{array}$ & $\begin{array}{l}4806 / 5739 \\
4275 / 5739\end{array}$ & $\begin{array}{l}(83.7) \\
(74.5)\end{array}$ & $\begin{array}{l}\text { TS } \\
\text { RM }\end{array}$ & $\begin{array}{l}5316 / 6368 \\
4745 / 6368\end{array}$ & $\begin{array}{l}(83.5) \\
(74.5)\end{array}$ & $\begin{array}{l}\text { TS } \\
\text { RM }\end{array}$ & $\begin{array}{l}0.82 \\
0.73\end{array}$ \\
\hline $\begin{array}{l}\text { Adaptive } \\
\text { boosting }\end{array}$ & $\begin{array}{l}\text { TS } \\
\text { RM }\end{array}$ & $\begin{array}{l}510 / 629 \\
473 / 629\end{array}$ & $\begin{array}{l}(81.1) \\
(75.2)\end{array}$ & $\begin{array}{l}\text { TS } \\
\text { RM }\end{array}$ & $\begin{array}{l}5561 / 5739 \\
4659 / 5739\end{array}$ & $\begin{array}{l}(88.0) \\
(81.2)\end{array}$ & $\begin{array}{l}\text { TS } \\
\text { RM }\end{array}$ & $\begin{array}{l}6071 / 6368 \\
5132 / 6368\end{array}$ & $\begin{array}{l}(87.3) \\
(80.6)\end{array}$ & $\begin{array}{l}\text { TS } \\
\text { RM }\end{array}$ & $\begin{array}{l}0.85 \\
0.77\end{array}$ \\
\hline Bagging & $\begin{array}{l}\text { TS } \\
\text { RM }\end{array}$ & $\begin{array}{l}473 / 629 \\
408 / 629\end{array}$ & $\begin{array}{l}(75.2) \\
(64.9)\end{array}$ & $\begin{array}{l}\text { TS } \\
\text { RM }\end{array}$ & $\begin{array}{l}5510 / 5739 \\
5528 / 5739\end{array}$ & $\begin{array}{l}(96.0) \\
(96.3)\end{array}$ & $\begin{array}{l}\text { TS } \\
\text { RM }\end{array}$ & $\begin{array}{l}5983 / 6368 \\
5936 / 6368\end{array}$ & $\begin{array}{l}(94.0) \\
(93.2)\end{array}$ & $\begin{array}{l}\text { TS } \\
\text { RM }\end{array}$ & $\begin{array}{l}0.86 \\
0.80\end{array}$ \\
\hline $\begin{array}{l}\text { Gradient } \\
\text { boosting }\end{array}$ & $\begin{array}{l}\text { TS } \\
\text { RM }\end{array}$ & $\begin{array}{l}512 / 629 \\
468 / 629\end{array}$ & $\begin{array}{l}(81.4) \\
(74.4)\end{array}$ & $\begin{array}{l}\text { TS } \\
\text { RM }\end{array}$ & $\begin{array}{l}5291 / 5739 \\
5073 / 5739\end{array}$ & $\begin{array}{l}(92.2) \\
(88.4)\end{array}$ & $\begin{array}{l}\text { TS } \\
\text { RM }\end{array}$ & $\begin{array}{l}5803 / 6368 \\
5541 / 6368\end{array}$ & $\begin{array}{l}(91.1) \\
(87.0)\end{array}$ & $\begin{array}{l}\text { TS } \\
\text { RM }\end{array}$ & $\begin{array}{l}0.87 \\
0.80\end{array}$ \\
\hline $\begin{array}{l}\text { Ensemble } \\
\text { voting }\end{array}$ & $\begin{array}{l}\text { TS } \\
\text { RM }\end{array}$ & $\begin{array}{l}512 / 629 \\
457 / 629\end{array}$ & $\begin{array}{l}(81.4) \\
(72.8)\end{array}$ & $\begin{array}{l}\text { TS } \\
\text { RM }\end{array}$ & $\begin{array}{l}5480 / 5739 \\
5536 / 5739\end{array}$ & $\begin{array}{l}(95.5) \\
(96.5)\end{array}$ & $\begin{array}{l}\text { TS } \\
\text { RM }\end{array}$ & $\begin{array}{l}5992 / 6368 \\
5993 / 6368\end{array}$ & $\begin{array}{l}(94.1) \\
(94.1)\end{array}$ & $\begin{array}{l}\text { TS } \\
\text { RM }\end{array}$ & $\begin{array}{l}0.88 \\
0.83\end{array}$ \\
\hline $\begin{array}{l}\text { Neural } \\
\text { network }\end{array}$ & $\begin{array}{l}\text { TS } \\
\text { RM }\end{array}$ & $\begin{array}{l}518 / 629 \\
384 / 629\end{array}$ & $\begin{array}{l}(82.4) \\
(61.1)\end{array}$ & $\begin{array}{l}\text { TS } \\
\text { RM }\end{array}$ & $\begin{array}{l}4911 / 5739 \\
5058 / 5739\end{array}$ & $\begin{array}{l}(85.6) \\
(88.1)\end{array}$ & $\begin{array}{l}\text { TS } \\
\text { RM }\end{array}$ & $\begin{array}{l}5429 / 6368 \\
5448 / 6368\end{array}$ & $\begin{array}{l}(85.3) \\
(85.5)\end{array}$ & $\begin{array}{l}\text { TS } \\
\text { RM }\end{array}$ & $\begin{array}{l}0.84 \\
0.76\end{array}$ \\
\hline
\end{tabular}

AUC Area under the curve 


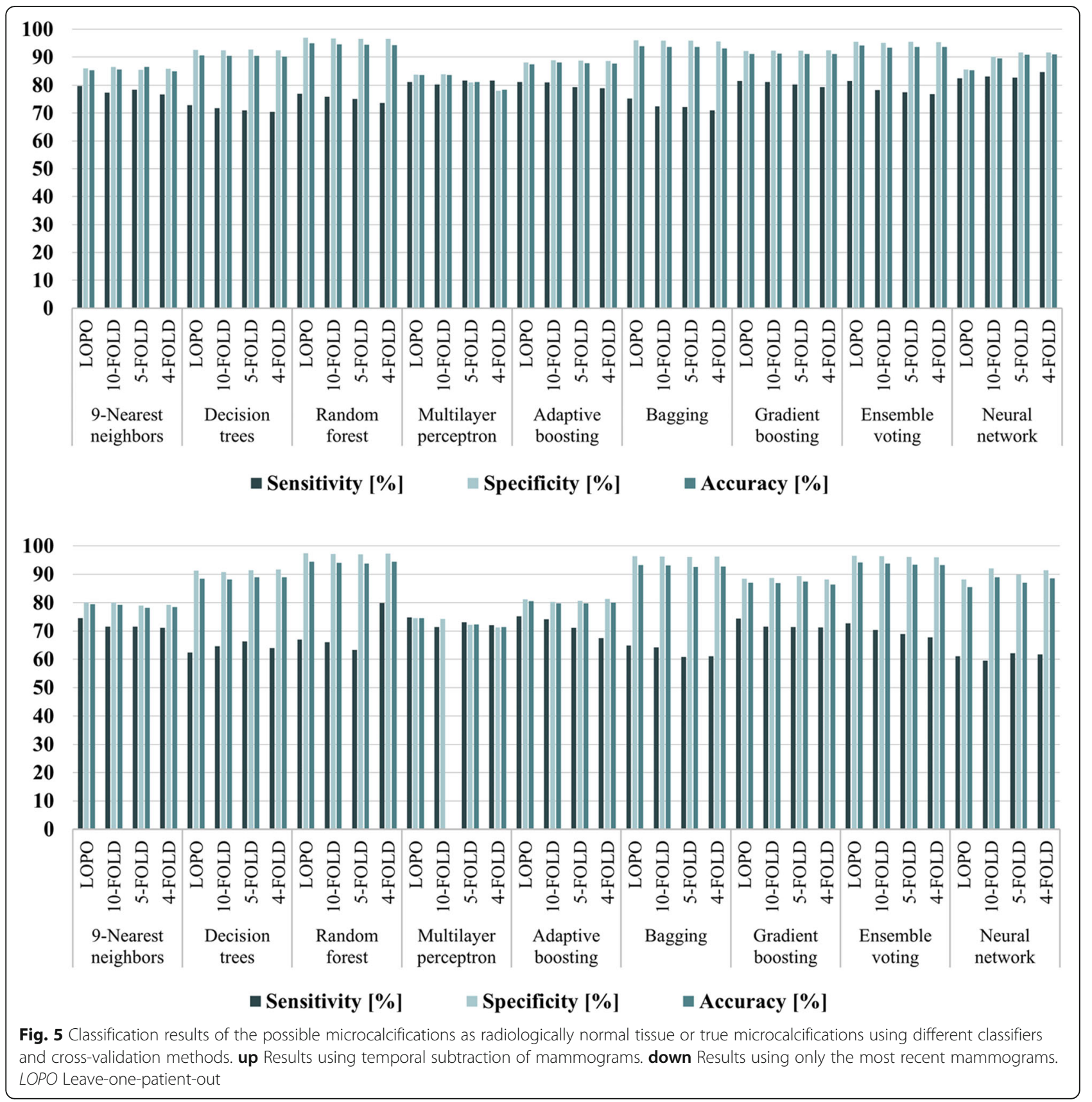

RADS benign or suspicious. Bagging, gradient boosting, ensemble voting, and neural networks are more recent additions to machine learning and were chosen for their potential to provide improved classification. Ideally, the proposed method should have also been verified on an independent external dataset. However, publicly available datasets do not provide sequential mammograms or images annotated at the level of individual microcalcifications.

Demons registration [19] was very effective in matching the prior to the recent mammographic views, since it accounted for the complex transformations and distortions that appear between screenings. Using the proposed technique, the contrast ratio improved $\sim 57$ times enhancing the contrast of the recent changes in the images. The elimination of most of the background and unchanged BI-RADS benign microcalcifications can make the radiologic evaluation of mammograms and the detection of even subtle abnormalities, easier and faster. This reduces the effort and time expended by the radiologist by enhancing the new and, most probably, more diagnostically useful information. 
Table 4 Comparison of the classification results of the true microcalcifications as BI-RADS benign or suspicious using temporal subtraction (TS) of mammograms and using only the most recent mammograms (RM), in a leave-one-patient-out cross-validation scheme

\begin{tabular}{|c|c|c|c|c|c|c|c|c|c|c|c|}
\hline \multirow{2}{*}{$\begin{array}{l}\text { Classifier } \\
\text { 9-Nearest } \\
\text { neighbors }\end{array}$} & \multicolumn{3}{|c|}{$\begin{array}{l}\text { Sensitivity } \\
\text { (\%) }\end{array}$} & \multicolumn{3}{|c|}{$\begin{array}{l}\text { Specificity } \\
\text { (\%) }\end{array}$} & \multicolumn{3}{|c|}{$\begin{array}{l}\text { Accuracy } \\
(\%)\end{array}$} & \multicolumn{2}{|c|}{ AUC } \\
\hline & $\begin{array}{l}\text { TS } \\
\text { RM }\end{array}$ & $\begin{array}{l}96 / 114 \\
73 / 114\end{array}$ & $\begin{array}{l}(84.2) \\
(64.0)\end{array}$ & $\begin{array}{l}\text { TS } \\
\text { RM }\end{array}$ & $\begin{array}{l}393 / 515 \\
357 / 515\end{array}$ & $\begin{array}{l}(76.3) \\
(69.3)\end{array}$ & $\begin{array}{l}\text { TS } \\
\text { RM }\end{array}$ & $\begin{array}{l}489 / 629 \\
430 / 629\end{array}$ & $\begin{array}{l}(77.7) \\
(68.4)\end{array}$ & $\begin{array}{l}\text { TS } \\
\text { RM }\end{array}$ & $\begin{array}{l}0.80 \\
0.67\end{array}$ \\
\hline $\begin{array}{l}\text { Decision } \\
\text { trees }\end{array}$ & $\begin{array}{l}\text { TS } \\
\text { RM }\end{array}$ & $\begin{array}{l}66 / 114 \\
65 / 114\end{array}$ & $\begin{array}{l}(57.9) \\
(57.0)\end{array}$ & $\begin{array}{l}\text { TS } \\
\text { RM }\end{array}$ & $\begin{array}{l}446 / 515 \\
445 / 515\end{array}$ & $\begin{array}{l}(86.6) \\
(86.4)\end{array}$ & $\begin{array}{l}\text { TS } \\
\text { RM }\end{array}$ & $\begin{array}{l}512 / 629 \\
510 / 629\end{array}$ & $\begin{array}{l}(81.4) \\
(81.1)\end{array}$ & $\begin{array}{l}\text { TS } \\
\text { RM }\end{array}$ & $\begin{array}{l}0.72 \\
0.72\end{array}$ \\
\hline $\begin{array}{l}\text { Random } \\
\text { forest }\end{array}$ & $\begin{array}{l}\text { TS } \\
\text { RM }\end{array}$ & $\begin{array}{l}73 / 114 \\
70 / 114\end{array}$ & $\begin{array}{l}(64.0) \\
(61.4)\end{array}$ & $\begin{array}{l}\text { TS } \\
\text { RM }\end{array}$ & $\begin{array}{l}461 / 515 \\
452 / 515\end{array}$ & $\begin{array}{l}(89.5) \\
(87.8)\end{array}$ & $\begin{array}{l}\text { TS } \\
\text { RM }\end{array}$ & $\begin{array}{l}534 / 629 \\
522 / 629\end{array}$ & $\begin{array}{l}(84.9) \\
(83.0)\end{array}$ & $\begin{array}{l}\text { TS } \\
\text { RM }\end{array}$ & $\begin{array}{l}0.77 \\
0.75\end{array}$ \\
\hline $\begin{array}{l}\text { Multilayer } \\
\text { perceptron }\end{array}$ & $\begin{array}{l}\text { TS } \\
\text { RM }\end{array}$ & $\begin{array}{l}93 / 114 \\
69 / 114\end{array}$ & $\begin{array}{l}(81.6) \\
(60.5)\end{array}$ & $\begin{array}{l}\text { TS } \\
\text { RM }\end{array}$ & $\begin{array}{l}411 / 515 \\
302 / 515\end{array}$ & $\begin{array}{l}(79.8) \\
(58.6)\end{array}$ & $\begin{array}{l}\text { TS } \\
\text { RM }\end{array}$ & $\begin{array}{l}504 / 629 \\
371 / 629\end{array}$ & $\begin{array}{l}(80.1) \\
(59.0)\end{array}$ & $\begin{array}{l}\text { TS } \\
\text { RM }\end{array}$ & $\begin{array}{l}0.81 \\
0.6\end{array}$ \\
\hline $\begin{array}{l}\text { Adaptive } \\
\text { boosting }\end{array}$ & $\begin{array}{l}\text { TS } \\
\text { RM }\end{array}$ & $\begin{array}{l}86 / 114 \\
80 / 114\end{array}$ & $\begin{array}{l}(75.4) \\
(70.2)\end{array}$ & $\begin{array}{l}\text { TS } \\
\text { RM }\end{array}$ & $\begin{array}{l}433 / 515 \\
430 / 515\end{array}$ & $\begin{array}{l}(84.1) \\
(83.5)\end{array}$ & $\begin{array}{l}\text { TS } \\
\text { RM }\end{array}$ & $\begin{array}{l}519 / 629 \\
510 / 629\end{array}$ & $\begin{array}{l}(82.5) \\
(81.1)\end{array}$ & $\begin{array}{l}\text { TS } \\
\text { RM }\end{array}$ & $\begin{array}{l}0.8 \\
0.77\end{array}$ \\
\hline Bagging & $\begin{array}{l}\text { TS } \\
\text { RM }\end{array}$ & $\begin{array}{l}69 / 114 \\
65 / 114\end{array}$ & $\begin{array}{l}(60.5) \\
(57.0)\end{array}$ & $\begin{array}{l}\text { TS } \\
\text { RM }\end{array}$ & $\begin{array}{l}458 / 515 \\
450 / 515\end{array}$ & $\begin{array}{l}(88.9) \\
(87.4)\end{array}$ & $\begin{array}{l}\text { TS } \\
\text { RM }\end{array}$ & $\begin{array}{l}527 / 629 \\
515 / 629\end{array}$ & $\begin{array}{l}(83.8) \\
(81.9)\end{array}$ & $\begin{array}{l}\text { TS } \\
\text { RM }\end{array}$ & $\begin{array}{l}0.75 \\
0.72\end{array}$ \\
\hline $\begin{array}{l}\text { Gradient } \\
\text { boosting }\end{array}$ & $\begin{array}{l}\text { TS } \\
\text { RM }\end{array}$ & $\begin{array}{l}82 / 114 \\
77 / 114\end{array}$ & $\begin{array}{l}(71.9) \\
(67.5)\end{array}$ & $\begin{array}{l}\text { TS } \\
\text { RM }\end{array}$ & $\begin{array}{l}447 / 515 \\
438 / 515\end{array}$ & $\begin{array}{l}(86.8) \\
(85.1)\end{array}$ & $\begin{array}{l}\text { TS } \\
\text { RM }\end{array}$ & $\begin{array}{l}529 / 629 \\
515 / 629\end{array}$ & $\begin{array}{l}(84.1) \\
(81.9)\end{array}$ & $\begin{array}{l}\text { TS } \\
\text { RM }\end{array}$ & $\begin{array}{l}0.79 \\
0.76\end{array}$ \\
\hline $\begin{array}{l}\text { Ensemble } \\
\text { voting }\end{array}$ & $\begin{array}{l}\text { TS } \\
\text { RM }\end{array}$ & $\begin{array}{l}93 / 114 \\
90 / 114\end{array}$ & $\begin{array}{l}(81.6) \\
(79.0)\end{array}$ & $\begin{array}{l}\text { TS } \\
\text { RM }\end{array}$ & $\begin{array}{l}475 / 515 \\
430 / 515\end{array}$ & $\begin{array}{l}(92.2) \\
(83.5)\end{array}$ & $\begin{array}{l}\text { TS } \\
\text { RM }\end{array}$ & $\begin{array}{l}568 / 629 \\
520 / 629\end{array}$ & $\begin{array}{l}(90.3) \\
(82.7)\end{array}$ & $\begin{array}{l}\text { TS } \\
\text { RM }\end{array}$ & $\begin{array}{l}0.87 \\
0.81\end{array}$ \\
\hline $\begin{array}{l}\text { Neural } \\
\text { network }\end{array}$ & $\begin{array}{l}\text { TS } \\
\text { RM }\end{array}$ & $\begin{array}{l}89 / 114 \\
83 / 114\end{array}$ & $\begin{array}{l}(78.1) \\
(72.8)\end{array}$ & $\begin{array}{l}\text { TS } \\
\text { RM }\end{array}$ & $\begin{array}{l}450 / 515 \\
485 / 515\end{array}$ & $\begin{array}{l}(87.4) \\
(94.2)\end{array}$ & $\begin{array}{l}\text { TS } \\
\text { RM }\end{array}$ & $\begin{array}{l}539 / 629 \\
568 / 629\end{array}$ & $\begin{array}{l}(85.7) \\
(90.3)\end{array}$ & $\begin{array}{l}\text { TS } \\
\text { RM }\end{array}$ & $\begin{array}{l}0.83 \\
0.83\end{array}$ \\
\hline
\end{tabular}

AUC Area under the curve

With automated BI-RADS classification, the proposed method achieved $81.4 \%$ sensitivity, $95.5 \%$ specificity and 94.1\% accuracy for the detection of true microcalcifications and $81.6 \%$ sensitivity, $92.2 \%$ specificity, and $90.3 \%$ accuracy for the classification of microcalcifications as BI-RADS benign or suspicious, both using an optimised feature set and an ensemble voting model. This high accuracy demonstrates the effectiveness of the algorithm, which provided statistically superior performance over using only the most recent mammograms. The average classification accuracy for the characterisation of true microcalcifications as BI-RADS benign or suspicious improved by $7 \%$ with the introduction of temporal subtraction $(p=0.003)$. To evaluate the robustness of the method, k-fold cross-validation was implemented, in addition to LOPO cross-validation. The algorithm performed at approximately the same level in all the crossvalidation scenarios, indicating that the proposed method is robust and should be able to function equally well as new data becomes available.

The main limitation of this study is the relatively limited dataset acquired from local hospitals with a single protocol. Even though the results presented here are promising, more sequential pairs are required to definitively prove the generalizability of the proposed algorithm. Unfortunately, publicly available databases cannot be exploited for the purposes of this project, since they neither contain sequential mammograms nor they include images annotated at the level of individual microcalcifications as in this study. Another limitation is the fact that although the suspicious microcalcifications were identified by two expert radiologists, the BI-RADS classification of clusters of microcalcifications not only varies from one radiologist to another, but might also be disproved by follow-up or pathology. In addition, the adoption of the BI-RADS classification as the ground truth, without any confirmation by follow-up or pathology, limits the generalizability and the ultimate utility of the tool. This is a consequence of mimicking the human reader rather than offering an unbiased opinion based on the true and confirmed state of the microcalcifications.

The results of this study cannot be readily and directly compared to other state-of-the-art techniques described in the literature for various reasons. The existing and freely available image databases contain only one mammogram per patient (i.e., no prior information). In addition, in several cases, entire images are classified rather than individual microcalcifications [34]. Furthermore, in most state-of-the-art algorithms, crossvalidation is implemented by randomly dividing the microcalcifications into training and test sets, or by using part of the same image in the test and another part in the training set [35]. Such approaches can introduce bias, which results in artificially improved classification results. In general, most studies in the literature report accuracy and AUC, which in the case of benign versus malignant classification of microcalcifications range 


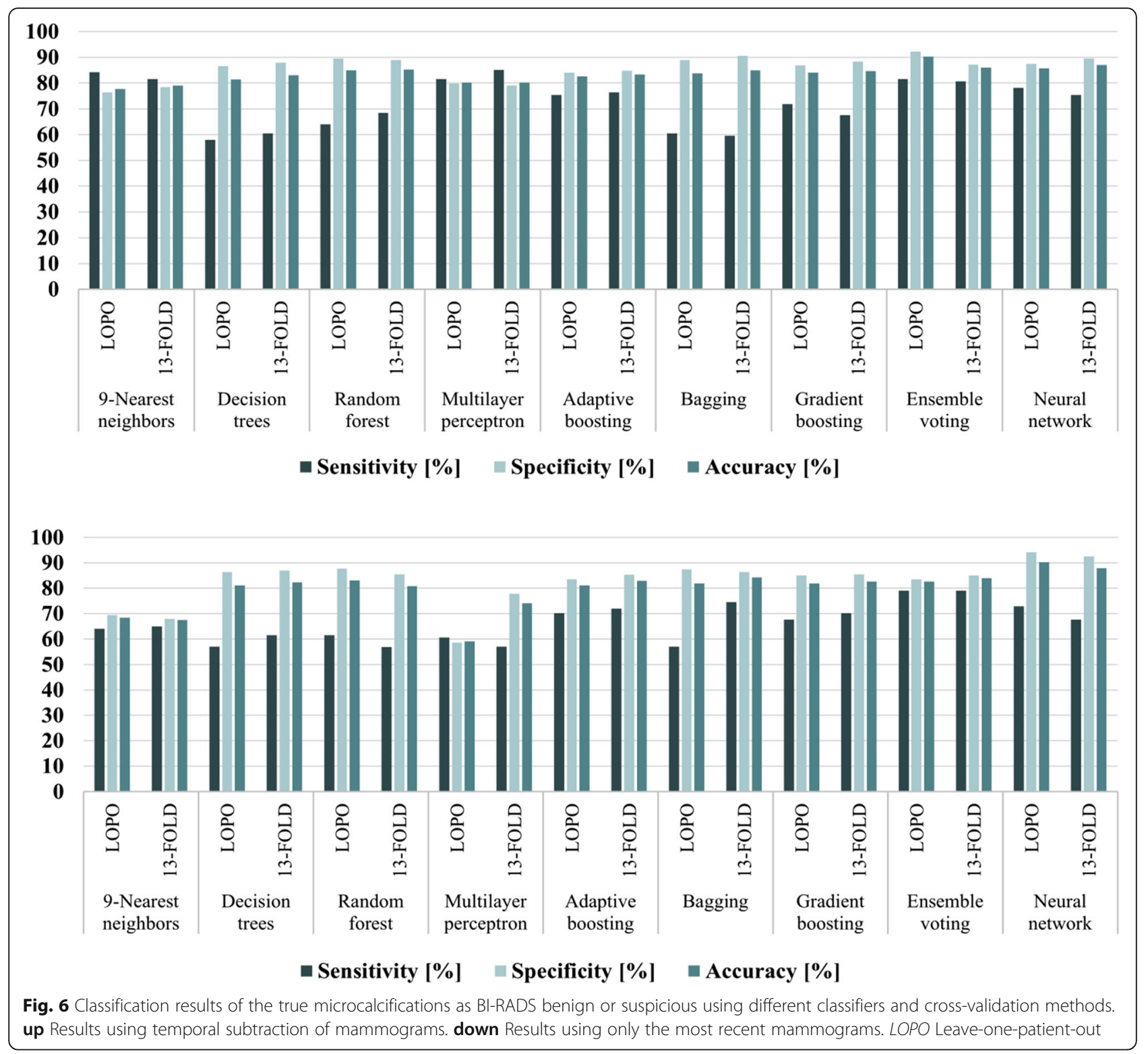

between $80-89 \%$ and $0.86-0.92 \%$ (Supplemental Table S2). In this study, a more appropriate approach was selected, which assigned the entire data set corresponding to a patient either to the training or the test set, and performed LOPO cross-validation. In order to prove the effectiveness of temporal subtraction in a fair manner, the results were compared to an optimised algorithm using only the most recent mammograms of the same dataset.

There are no examples of temporal analysis for microcalcification identification and classification in the literature. Furthermore, there are only a few studies on the use of temporal analysis for the characterisation of mass lesions $[9-11,13]$. Rather than image subtraction, their approach was to extract several features from the recent and prior mammograms separately and, then, combine them to improve the classification accuracy. Their results confirmed that the use of prior information could improve the detection and classification of mass lesions. However, temporal analysis offers no benefit when there is no abnormality in the prior screening.

In conclusion, the proposed technique demonstrates that temporal subtraction achieves superior performance in the detection and classification of microcalcifications, based on their BI-RADS category, compared to using only the most recent mammograms. The inclusion of more patients as well as the extension of the approach to detect and classify other abnormalities in mammograms (e.g., breast masses or distortions) can further enhance the diagnostic potential of temporal subtraction. In the future, the proposed methodology has the 
potential to substantially contribute to the development of automated CAD systems to assist in the radiologic classification of breast abnormalities and serve as a "second reader" or a "tie breaker" especially in low resource settings.

\section{Abbreviations}

AUC: Area under the curve; BI-RADS: Breast Imaging Reporting and Data System; CAD: Computer-aided diagnosis; FP: False positive; GLCM: Grey-level co-occurrence matrix; LOPO: Leave-one-patient-out

\section{Supplementary Information}

The online version contains supplementary material available at https://doi. org/10.1186/s41747-021-00238-w.

\begin{abstract}
Additional file1 Supplemental Fig. S1 Diagram of the proposed methodology for the detection and BI-RADS classification of breast microcalcifications using temporal subtraction of sequential mammograms. Supplemental Table S1 Features selected for the 1st and 2nd round of BIRADS classification using temporal subtraction and only the most recent mammograms. Supplemental Fig. S2 Results of the classification of the radiologically true microcalcifications as BI-RADS benign or suspicious in the most recent mammographic view of a woman (BI-RADS breast density class b). (a) Most recent mammographic view, with green circles around the BI-RADS benign microcalcifications, and a red circle around the BI-RADS suspicious microcalcifications. (b) Zoomed view of the red square in a with BI-RADS suspicious microcalcifications. (c) Zoomed view of the green square in a with BI-RADS benign microcalcifications. Supplemental Table S2 Comparison of accuracy and AUC of different state-ofthe-art techniques for the classification of benign versus malignant microcalcifications [36-40].
\end{abstract}

\section{Acknowledgements}

This study was funded by the European Union's Horizon 2020 research and innovation program under grant agreement No. 739551 (KIOS CoE) and from the Republic of Cyprus through the Directorate General for European Programs, Coordination and Development.

\section{Authors' contributions}

$\mathrm{CP}$ was the guarantor of integrity of the entire study. $\mathrm{KL}, \mathrm{CP}$, and $\mathrm{CN}$ defined the basic concepts of the study. KL analysed the literature. GS and CN collected and selected the dataset. $\mathrm{KL}$ and $\mathrm{CP}$ developed the algorithm. KL performed the statistical analysis and analysed the results. KL prepared the first draft of the manuscript with all the figures and tables. $K L, G S, C P$, and $\mathrm{CN}$ edited the manuscript. All authors read and approved the final manuscript.

\section{Funding}

This study has received funding by the European Union's Horizon 2020 research and innovation program under grant agreement No. 739551 (KIOS $\mathrm{COE}$ ) and from the Republic of Cyprus through the Directorate General for European Programs, Coordination and Development.

\section{Availability of data and materials}

The dataset generated during the current study is publicly available through Zenodo. The dataset can be accessed using the following link: https://doi. org/10.5281/zenodo.5036062.

\section{Declarations}

\section{Ethics approval and consent to participate}

The study was approved by the local Institutional Review Board. Written informed consent was obtained from all patients.

\section{Consent for publication}

Not applicable.

\section{Competing interests}

The authors declare that they have no competing interests.

\section{Author details}

${ }^{1} \mathrm{KIOS}$ Research and Innovation Center of Excellence, Department of Electrical and Computer Engineering, University of Cyprus, 1 Panepistimiou Avenue, Aglantzia, 2109 Nicosia, Cyprus. ${ }^{2}$ Nicosia General Hospital, 215 Nicosia-Limassol Old Road, Strovolos, 2029 Nicosia, Cyprus. ${ }^{3}$ Limassol General Hospital, 1 Nikaias, 4131 Limassol, Cyprus.

Received: 30 March 2021 Accepted: 4 August 2021

Published online: 14 September 2021

\section{References}

1. Ganesan K, Acharya UR, Chua CK, Min LC, Abraham KT, Ng KH (2013) Computer-aided breast cancer detection using mammograms: a review. IEEE Rev Biomed Eng 6:77-98. https://doi.org/10.1109/RBME.2012.2232289

2. Arancibia Hernández PL, Taub Estrada T, López Pizarro A, Díaz Cisternas ML, Sáez Tapia C (2016) Breast calcifications: description and classification according to BI-RADS 5th edition. Rev Chil Radiol 22:80-91. https:/doi.org/1 0.1016/j.rchira.2016.06.004

3. Burnside ES, Ochsner JE, Fowler KJ, et al (2007) Use of microcalcification descriptors in BI-RADS 4th edition to stratify risk of malignancy. Radiology 242:388-395. https://doi.org/10.1148/radiol.2422052130

4. Singh S, Maxwell J, Baker JA, Nicholas JL, Lo JY (2011) Computer-aided classification of breast masses: Performance and interobserver variability of expert radiologists versus residents. Radiology 258:73-80. https://doi.org/1 0.1148 /radiol.10081308

5. Cheng HD, Cai X, Chen X, Hu L, Lou X (2003) Computer-aided detection and classification of microcalcifications in mammograms: a survey. Pattern Recogn 36:2967-2991. https://doi.org/10.1016/S0031-3203(03)00192-4

6. Rodríguez-Ruiz A, Krupinski E, Mordang JJ, et al (2019) Detection of breast cancer with mammography: Effect of an artificial intelligence support system. Radiology 290:305-314. https://doi.org/10.1148/radiol.2018181371

7. Kumar MNA, Kumar MNA, Sheshadri HS (2019) Computer aided detection of clustered microcalcification: a survey. Curr Med Imaging Rev 15:132-149. https://doi.org/10.2174/1573405614666181012103750

8. Nishikawa RM, Kallergi M, Orton CG (2006) Computer-aided detection, in its present form, is not an effective aid for screening mammography. Med Phys 33:812-814. https://doi.org/10.1118/1.2168063

9. Hadjiiski L, Sahiner B, Chan HP, Petrick N, Helvie MA, Gurcan M (2001) Analysis of temporal changes of mammographic features: computer-aided classification of malignant and benign breast masses. Med Phys 28:23092317. https://doi.org/10.1118/1.1412242

10. Varela C, Karssemeijer N, Hendriks JHCL, Holland R (2005) Use of prior mammograms in the classification of benign and malignant masses. Eur $\mathrm{J}$ Radiol 56:248-255. https://doi.org/10.1016/j.ejrad.2005.04.007

11. Timp S, Varela C, Karssemeijer N (2007) Temporal change analysis for characterization of mass lesions in mammography. IEEE Trans Med Imaging 26:945-953. https://doi.org/10.1109/TMl.2007.897392

12. Roelofs AAJ, Karssemeijer N, Wedekind N, et al (2007) Importance of comparison of current and prior mammograms in breast cancer screening. Radiology 242:70-77. https://doi.org/10.1148/radiol.2421050684

13. Timp S, Varela C, Karssemeijer N (2010) Computer-aided diagnosis with temporal analysis to improve radiologists interpretation of mammographic mass lesions. IEEE Trans Inf Technol Biomed 14:803-808. https://doi.org/1 $0.1109 /$ TITB.2010.2043296

14. Hakim CM, Catullo VJ, Chough DM, et al (2015) Effect of the availability of prior full-field digital mammography and digital breast tomosynthesis images on the interpretation of mammograms. Radiology 276:65-72. https:/doi.org/1 $0.1148 /$ radiol.15142009

15. Loizidou K, Skouroumouni G, Nikolaou C, Pitris C (2019) A new method for breast micro-calcification detection and characterization using digital temporal subtraction of mammogram pairs. In: 2019 IEEE EMBS International Conference on Biomedical and Health Informatics, BHI 2019 Proceedings, pp 1-4

16. Loizidou K, Skouroumouni G, Nikolaou C, Pitris C (2020) An automated breast micro-calcification detection and classification technique using temporal subtraction of mammograms. IEEE Access 8:52785-52795. https:// doi.org/10.1109/ACCESS.2020.2980616 
17. Gonzalez RC, Woods RE, Eddins SL (2010) Digital image processing using Matlab, 2nd edn. Tata McGraw-Hill

18. Huang SC, Cheng FC, Chiu YS (2012) Efficient contrast enhancement using adaptive gamma correction with weighting distribution. IEEE Trans Image Process 22:1032-1041. https://doi.org/10.1109/TIP.2012.2226047

19. Pennec X, Cachier P, Ayache N (1999) Understanding the "demon's algorithm": 3D non-rigid registration by gradient descent. Lect Notes Comput Sci 1679:597-606. https://doi.org/10.1007/10704282_64

20. Díez Y, Oliver A, Lladó X et al (2011) Revisiting intensity-based image registration applied to mammography. IEEE Trans Inf Technol Biomed 15: 716-725. https://doi.org/10.1109/TITB.2011.2151199

21. Bailey D, Hodgson R (1985) Range filters: Localintensity subrange filters and their properties. Image Vis Comput 3:99-110. https://doi.org/10.1016/02628856(85)90058-7

22. Singh B, Kaur M (2018) An approach for classification of malignant and benign microcalcification clusters. Sadhana 43:1-18. https://doi.org/10.1007/ s12046-018-0805-2

23. Kumar V, Gupta P (2012) Importance of statistical measures in digital image processing. Int J Emerg Technol Adv Eng 2:56-62

24. Haralick RM, Dinstein I, Shanmugam K (1973) Textural features for image classification. IEEE Trans Syst Man Cybern SMC-3:610-621. https://doi.org/1 0.1109/TSMC.1973.4309314

25. Diehr P, Martin DC, Koepsell T, Cheadle A (1995) Breaking the matches in a paired t-test for community interventions when the number of pairs is small. Stat Med 14:1491-1504. https://doi.org/10.1002/sim.4780141309

26. Pedregosa F, Varoquaux G, Gramfort A et al (2011) Scikit-learn: machine learning in Python. J Mach Learn Res 12:2825-2830

27. Alam N, Denton ERE, Zwiggelaar R (2019) Classification of microcalcification clusters in digital mammograms using a stack generalization based classifier. J Imaging 5. https://doi.org/10.3390/jimaging5090076

28. Mohebian MR, Marateb HR, Mansourian M, Mañanas MA, Mokarian F (2017) A hybrid computer-aided-diagnosis system for prediction of breast cancer recurrence (HPBCR) using optimized ensemble learning. Comput Struct Biotechnol J 15:75-85. https://doi.org/10.1016/j.csbj.2016.11.004

29. Pak F, Kanan HR, Alikhassi A (2015) Breast cancer detection and classification in digital mammography based on Non-Subsampled Contourlet Transform (NSCT) and Super Resolution. Comput Methods Prog Biomed 122:89-107. https://doi.org/10.1016/j.cmpb.2015.06.009

30. Breiman L (1996) Bagging predictors. Mach Learn 24:123-140. https://doi. org/10.1007/bf00058655

31. Friedman JH (2002) Stochastic gradient boosting. Comput Stat Data Anal 38:367-378. https://doi.org/10.1016/S0167-9473(01)00065-2

32. Raschka S (2015) Python machine learning: unlock deeper insights into machine learning with this vital guide to cutting-edge predictive analytics, 1st edn. Packt Publishing

33. Yassin NIR, Omran S, El Houby EMF, Allam H (2018) Machine learning techniques for breast cancer computer aided diagnosis using different image modalities: a systematic review. Comput Methods Prog Biomed 156: 25-45. https://doi.org/10.1016/j.cmpb.2017.12.012

34. Li H, Zhuang S, Dao L, Zhao J, Ma Y (2019) Benign and malignant classification of mammogram images based on deep learning. Biomed Signal Process Control 51:347-354. https://doi.org/10.1016/j.bspc.2019.02.017

35. Yu S, Guan L (2000) A CAD system for the automatic detection of clustered microcalcifications in digitized mammogram films. IEEE Trans Med Imaging 19:115-126. https://doi.org/10.1109/42.836371

36. Ren J (2012) ANN vs. SVM: Which one performs better in classification of MCCs in mammogram imaging. Knowledge-Based Syst 26. https://doi.org/1 0.1016/j.knosys.2011.07.016

37. Khehra BS, Partap A, Pharwaha S (2013) Least-Squares Support Vector Machine for Characterization of Clusters of Microcalcifications. 7:1612-1621

38. Strange $H$, Chen Z, Denton ERE, Zwiggelaar R (2014) Modelling mammographic microcalcification clusters using persistent mereotopology. Pattern Recogn Lett 47:157-163. https://doi.org/10.1016/.jpatrec.2014.04.008

39. Chen Z, Strange H, Oliver A, Denton ERE, Boggis C, Zwiggelaar R (2015) Topological modeling and classification of mammographic microcalcification clusters. IEEE Trans Biomed Eng 62:-1214. https://doi.org/1 0.1109/TBME.2014.2385102

40. Fanizzi A, Basile TMA, Losurdo L, et al (2020) A machine learning approach on multiscale texture analysis for breast microcalcification diagnosis. BMC Bioinformatics 21:91. https://doi.org/10.1186/s12859-020-3358-4

\section{Publisher's Note}

Springer Nature remains neutral with regard to jurisdictional claims in published maps and institutional affiliations.

\section{Submit your manuscript to a SpringerOpen ${ }^{\circ}$ journal and benefit from:}

- Convenient online submission

- Rigorous peer review

- Open access: articles freely available online

High visibility within the field

- Retaining the copyright to your article

Submit your next manuscript at $\boldsymbol{\nabla}$ springeropen.com 